\title{
Evaluation of orofacial motricity in patients with mucopolysaccharidosis: a cross-sectional study
}

\author{
Giovana S. Turra, ${ }^{1}$ Ida Vanessa D. Schwartz ${ }^{2}$
}

\begin{abstract}
Objective: To characterize the stomatognathic system and stomatognathic functions in patients with mucopolysaccharidosis.

Methods: Cross-sectional and observational study of patients with mucopolysaccharidosis seen at the outpatient clinic at the Medical Genetics Service of Hospital de Clínicas de Porto Alegre. The inclusion criteria were the existence of a biochemical or molecular diagnosis of any type of mucopolysaccharidosis and the agreement to participate in the study by signing an informed consent form. Seventy-eight patients were evaluated through phonoaudiological anamnesis and physical exam.

Results: Alterations in at least one item of each structure of the stomatognathic system or stomatognathic function were found in all patients who allowed evaluation of both items on physical examination $(n=76 / 78)$. The most frequently compromised structures and functions were respectively the dental arch and the tongue, swallowing and mastication. The only statistically significant difference found between types of mucopolysaccharidosis involved the habitual position of the tongue between the teeth (most frequent in mucopolysaccharidosis VI). Among patients with mucopolysaccharidosis I, II or VI who underwent enzyme replacement therapy or not, there was statistically significant difference in oral breathing mode (more frequent in the group without enzyme replacement therapy).

Conclusions: Alterations in stomatognathic systems and functions are prevalent among individuals with mucopolysaccharidosis, even if enzyme replacement therapy is administered. Such finding suggests that speech therapy follow-up plays a major role in the treatment plan of this group of diseases; this hypothesis should be confirmed by additional studies.
\end{abstract}

J Pediatr (Rio J). 2009;85(3):254-260: Mucopolysaccharidosis, speech therapy, stomatognathic system.

\section{Introduction}

Mucopolysaccharidoses (MPS) are genetic diseases caused by the deficient activity of enzymes that degrade glycosaminoglycans (GAGs) and by the consequent accumulation of these macromolecules inside lysosomes. ${ }^{1}$ The MPS are classified according to the deficient enzyme as: MPS I ( $\alpha$-L-iduronidase deficiency), MPS II (iduronate-sulfatase deficiency), MPS III-A (heparan N-sulfatase deficiency), MPS III-B ( $\alpha$-N-acetylglucosaminidase deficiency), MPS
III-C (acetyl-CoA- $\alpha$-glucosaminide acetyltransferase deficiency), MPS III-D ( $\mathrm{N}$-acetylglucosamine 6-sulfatase deficiency), MPS IV-A ( $\mathrm{N}$-acetylgalactosamine 6-sulfatase deficiency), MPS IV-B ( $\beta$-galactosidase deficiency), MPS VI ( $\mathrm{N}$-acetylgalactosamine-4-sulfatase deficiency), MPS VII ( $\beta$-glucuronidase deficiency), and MPS IX (hyaluronidase deficiency). It is estimated that the combined incidence of this group of diseases is $1: 25,000$ live newborns. ${ }^{2}$

1. MSc, Medicine, Medical Sciences, Universidade Federal do Rio Grande do Sul (UFRGS), Porto Alegre, RS, Brazil.

2. PhD, Sciences, Genetics, UFRGS, Porto Alegre, RS, Brazil. Associate professor, Department of Genetics, UFRGS, Porto Alegre, RS, Brazil.

This paper is part of the Graduate Program in Medicine: Medical Sciences, Universidade Federal do Rio Grande do Sul (UFRGS), Medical Genetics Service, Hospital de Clínicas de Porto Alegre, and Department of Genetics, UFRGS, Porto Alegre, RS, Brazil.

Financial support: Rede MPS Brasil, CAPES.

No conflicts of interest declared concerning the publication of this article.

Suggested citation: Turra GS, Schwartz IV. Evaluation of orofacial motricity in patients with mucopolysaccharidosis: a cross-sectional study. J Pediatr (Rio J). 2009;85(3):254-260.

Manuscript received January 12 2009, accepted for publication April 12009

doi:10.2223/JPED.1899 
Each type of MPS is associated with great clinical heterogeneity. As to MPS I, for instance, its most severe form (characterized by mental retardation, severe somatic involvement and death before the age of 10 years) is usually called Hurler syndrome. Its mild form (characterized by preserved cognition and less somatic involvement) is called Scheie syndrome. ${ }^{3}$ In all MPS types, the following findings are frequent: macrocephaly, hepatosplenomegaly, umbilical and inguinal hernias, bone dysplasia, delayed motor development, hearing loss, respiratory difficulty, facial and dental alterations, enlarged tongue, heart disease, and limitation of joint mobility. Corneal clouding is not frequent in MPS II, III and IV; MPS IV and VI are not usually associated with mental retardation. ${ }^{4-6}$

MPS treatment may be symptomatic or specific. Symptomatic treatment addresses the disease complications, such as the use of medication for heart insufficiency. The specific treatment seeks to replace the deficient enzyme, and includes when recommended hematopoietic cells transplantation and enzyme replacement therapy (ERT); the latter is available for MPS I, II and VI. ${ }^{10-12}$

In the literature there are few studies regarding speech and language evaluation in patients with MPS, and most are focused on aspects related to speech and language development. ${ }^{13-15}$ The main objective of this study was to describe the alterations found in the stomatognathic system and functions of patients with MPS.

\section{Methods}

This is a cross-sectional and observational study, approved by the Research Ethics Committee of Hospital de Clínicas de Porto Alegre (HCPA). The study assessed patients with MPS seen at the MPS outpatient clinics of the Medical Genetics Service at HCPA, which is an international reference center for the diagnosis and treatment of this group of diseases. The patients were invited to participate in the study at one of their visits to the clinics in 2006/2007 and were included in the study only after signing an informed consent form. Inclusion criterion was existence of biochemical or molecular diagnosis of any type of MPS. The situation of current or past treatment was not part of the inclusion or exclusion criteria.

Assessment comprised phonoaudiological anamnesis, physical exam, and medical file review. Anamnesis and physical exam were based on Bianchini, Junqueira, Morales and Marchesan ${ }^{16-19}$ and were performed by phonoaudiologist that wrote this paper, not blinded to patients' treatment status, on a consultation of around one hour. Anamnesis was obtained from the patient or guardian. Physical examination consisted of evaluation of stomatognathic system structures (lips, tongue, cheeks, mandible, hard palate, soft palate, palatine tonsils and dental arch) and stomatognathic functions (suction, mastication, swallowing, breathing and speech). Examination of tongue, cheeks, palate, palatine tonsils and teeth was performed with the aid of gloves, spatula and flashlight. Evaluation of mastication was performed using solid food (bread roll); solid food (bread roll) and liquid (water) in a glass for swallowing; and plastic straw and liquid (water) in a glass for suction.

Data were grouped into a Microsoft Excel table and further analyzed using the Statistical Package for the Social Sciences (SPSS) 14.0 for Windows. Variables with data available to more than $50 \%$ of the sample were analyzed. Categorical variables were summarized by means of frequencies and percentages. Continuous variables with normal distribution were summarized by mean and standard deviation values, while those with asymmetrical distribution were summarized by means of median values and interquartile ranges. MPS types that individually corresponded to over $10 \%$ of the sample were compared as to the most frequent alterations found in each of the stomatognathic structures and functions assessed. MPS I, II and VI patients on ERT or not on ERT were also compared as to these variables; due to the sample size, the effect of ERT was not analyzed according to the exposed MPS subgroups. Statistical tests used to perform such comparisons were chi-square or Fisher's exact test applying Bonferroni's correction.

Patients were not compared in relation to being or not on phonoaudiological treatment because exposure to this type of intervention was not homogenous in the sample, including different professionals and techniques, in addition to a different number of weekly sessions.

\section{Results}

Eighty-six patients with MPS were evaluated at the Medical Genetics Service of HCPA during the study period (MPS I $=15 ;$ MPS II $=37$; MPS III-B $=2$; MPS IV-A = 5; MPS VI $=27$ ). Of these, 78 agreed to participate and their data are summarized in Table 1 . As to origin, 74/78 patients were Brazilian: 29 (39.2\%) from the South, $26(35.1 \%)$ from the Southeast, $14(18.9 \%)$ from the Northeast, three $(4.1 \%)$ from the North, and two $(2.7 \%)$ from the Midwest. Mental retardation was present in $17 / 78$ (21.8\%) patients (MPS I severe form $=4 / 14$ or $28.6 \%$; MPS II severe form $=11 / 35$ or $31.4 \%$; and MPS III-B = $2 / 2$ ). Major visual deficit was present in $9 / 78$ (11.5\%) patients, all with MPS VI. Two patients had a tracheotomy tube (both had MPS VI). MPS I, II and VI each accounted for more than $10 \%$ of the total sample, and were included in subgroup analysis. During the evaluation, 18 patients were receiving phonoaudiological treatment, and 40 were given ERT (at the Medical Genetics Service of HCPA).

\section{Anamnesis}

In terms of maternal breastfeeding, $62 / 76$ (81.6\%) 
Table 1 - Characterization of patients with MPS evaluated in this study $(n=78)$

\begin{tabular}{|c|c|c|c|c|}
\hline Type of MPS & $\begin{array}{l}\text { Patients } \\
\text { (n) }\end{array}$ & $\begin{array}{c}\text { Gender } \\
\text { (male/female) }\end{array}$ & $\begin{array}{c}\text { Mean age at evaluation } \\
\pm \text { SD (years) }\end{array}$ & $\begin{array}{c}\text { Number of patients } \\
\text { in ERT* }\end{array}$ \\
\hline MPS I & 14 & $5 / 9$ & $12.6 \pm 9.4$ & $11(10 ; 6-18)$ \\
\hline MPS II & 35 & $35 / 0$ & $11.9 \pm 6.5$ & $19(25 ; 18-30)$ \\
\hline MPS III-B & 2 & $1 / 1$ & $11.0 \pm 2.8$ & 0 \\
\hline MPS IV-A & 4 & $2 / 2$ & $11.0 \pm 3.4$ & 0 \\
\hline MPS VI & 23 & $13 / 10$ & $10.4 \pm 4.7$ & $10(19 ; 14.2-24.5)$ \\
\hline Total & 78 & $56 / 22$ & $11.5 \pm 6.4$ & $40(19.5 ; 14-26)$ \\
\hline
\end{tabular}

ERT = enzyme replacement therapy; MPS = mucopolysaccharidosis; SD = standard deviation.

* Median in months of ERT; interquartile range.

patients were breastfed at some time in their lives (median of breastfeeding time $=6$ months; interquartile range $=3-18)$; of these, four (6.4\%) were foreigners. Median of breastfeeding time considering only Brazilian patients was 8 months (interquartile range $=3-18$ ). Use of baby bottle occurred in 69/76 (90.8\%) patients (median of baby bottle use $=30$ months; interquartile range $=15.7-58.5)$. Use of pacifier was reported by $53 / 77$ $(68.8 \%)$ patients (median of pacifier use $=36$ months; interquartile range $=24-72$ )

Information on food consistency consumed until 2 years of age was obtained from $74 / 78$ patients, being adequate in $62 / 74(83.8 \%)$ The other patients consumed only pasty foods until 2 years of age. At the time of the study, consistency of the food was normal in $66 / 77$ (85.7\%) patients (the others ingested only pasty foods). In terms of deleterious habits, there was presence of onychophagia in $13 / 77(16.9 \%)$ patients and bruxism in $7 / 77(9.1 \%)$. With regard to sleep, $48 / 73(65.7 \%)$ reported occurrence of drooling, 35/78 (44.9\%) reported snoring, and 23/76 (30.3\%) reported apnea. As to previous surgeries, 42/76 (55.3\%) patients had undergone adenoidectomy, 25/76 (32.9\%) myringotomy with placement of ventilating tubes, and $18 / 76(23.7 \%)$ tonsillectomy.

\section{Physical examination}

Cognitive, visual and joint deficits found in many patients made physical examination difficult, especially in items regarding stomatognathic functions. Physical examination could not be performed in one patient (MPS I severe form); in another patient (also MPS I severe form) any function could be evaluated, only the stomatognathic system was partially evaluated and had normal results. All the other patients had some abnormality on physical exam, which is summarized in Tables 2 and 3. The most frequently impaired structures of the stomatognathic system were the dental arch and tongue ( 98.4 and $95.9 \%$ of patients, respectively, had some type of change); the other structures (lips, cheeks, mandible and hard palate) were each compromised in $70-90 \%$ of patients. The most impaired functions were swallowing and mastication ( 98.5 and $95.3 \%$ of patients, respectively, had some type of change); the other functions (suction, breathing and speech) were each impaired in 65$80 \%$ of patients. Soft palate and palatine tonsils could not be evaluated in more than $50 \%$ of the sample. For that reason, such variables were not included in Table 2 .

MPS I, II and VI were compared in relation to frequency of the most prevalent changes on physical exam (Table 4). When Bonferroni's correction was applied, only the habitual position of the tongue between teeth had significant statistical difference (more frequent in MPS VI). In a comparison of groups with and without ERT, after application of Bonferroni's correction, there was significant statistical difference only in relation to oral breathing mode (more frequent in the group without ERT).

\section{Discussion}

MPS are severe, chronic, multisystemic genetic diseases associated with wide heterogeneity and high morbidity and mortality rate in childhood. ${ }^{1,20}$ Although clinical suspicion of MPS can be easily performed by a basic healthcare professional when the patient has the complete extent of the disease (that is, in more advanced stages), its identification in earlier stages or in mild or atypical cases is more difficult and requires a deeper knowledge of the disease.

The diagnostic path that MPS patients have to follow is long and expensive: in average diagnosis is performed 4.8 years after symptom onset; during this period, such patients see four to five specialists in average, require one to two hospitalizations and are submitted to one or two surgical procedures. ${ }^{21}$ In addition, confirmation of diagnosis (and type of MPS as each type is caused by a specific enzyme deficiency) is dependent on complex laboratorial tests that are not currently available in the Brazilian public health system. 
As a consequence, mean diagnostic age in Brazilian patients (76 months) is higher than the double of that found in developed countries. ${ }^{21}$ Since the pediatrician is the health professional most frequently sought by patients/relatives with MPS when clinical manifestations occur, $^{21}$ it is crucial that such professionals know about the clinical signs associated with this group of diseases, as well as of the currently available possibilities of management and treatment.
Within such context, this study indicates that alterations in lips, tongue, cheeks, mandible, hard palate and dental arch are frequent in patients with MPS, as well as their functional correspondents (suction, mastication, swallowing, breathing and speech). Such finding is in accordance with what is expected from the information available in the literature on orofacial motricity and MPS, which particularly comes from chapters of specialized books about inborn errors of metabolism. ${ }^{1,20}$ This article is the first to present

Table 2 - Evaluation of stomatognathic structures of patients with MPS*†

\begin{tabular}{|c|c|c|}
\hline Stomatognathic structures & Most frequent finding ( $\%)$ & Second most frequent finding $(\%)$ \\
\hline \multicolumn{3}{|l|}{ Lips $(n=77)$} \\
\hline Aspect & Normal (53.2) & Shortened upper (20.8); everted lower(20.8) \\
\hline Habitual position & Separated (66.2) & Sealed (33.8) \\
\hline Upper tonus & Normal (71.4) & Hypofunctional (20) \\
\hline Lower tonus & Normal (64.3) & Hypofunctional (27.1) \\
\hline \multicolumn{3}{|l|}{ Mobility } \\
\hline Stretching & Normal (100) & - \\
\hline Protrusion & Normal (100) & - \\
\hline Vibration & Normal (84.7) & Difficulty to perform the movement (15.3) \\
\hline Lateralization & Normal (81.1) & Difficulty to perform the movement (18.9) \\
\hline Frenulum & Normal (100) & - \\
\hline Mentalis muscle tonus & Hyperfunctional (93.2) & Normal (6.8) \\
\hline \multicolumn{3}{|l|}{ Tongue $(n=74)$} \\
\hline Aspect & Normal (64.3) & Enlarged (32.9) \\
\hline Tonus & Normal (62.9) & Hypofunctional (37.1) \\
\hline Habitual position & Between teeth (49.3) & Inferior alveolar region (45.2) \\
\hline \multicolumn{3}{|l|}{ Mobility } \\
\hline Protrusion & Normal (100) & - \\
\hline Vibration & Normal (67.3) & Difficulty to perform the movement (32.7) \\
\hline Widening & Normal (90.9) & Difficulty to perform the movement (9.1) \\
\hline Crackling & Normal (83.9) & Difficulty to perform the movement (16.1) \\
\hline Elevation & Normal (94.6) & Difficulty to perform the movement (5.4) \\
\hline Lateralization & Normal (92.9) & Difficulty to perform the movement (7.1) \\
\hline Frenulum & Normal (98.2) & Short (1.8) \\
\hline \multicolumn{3}{|l|}{ Cheeks $(n=69)$} \\
\hline Appearance & Asymmetric (76.6) & Symmetric (23.4) \\
\hline Internal tonus & Normal (82.5) & Hypofunctional (12.3) \\
\hline Mobility & Normal (98.3) & Difficulty to perform the movement (1.7) \\
\hline Internal teeth marks & Absence (92.6) & Presence (7.4) \\
\hline \multicolumn{3}{|l|}{ Mandible $(n=59)$} \\
\hline \multicolumn{3}{|l|}{ Mobility } \\
\hline Opening & Normal (81.4) & Difficulty to perform the movement (18.6) \\
\hline Rotation & Difficulty to perform the movement (74.5) & Normal (25.5) \\
\hline Lateralization & Normal (70.9) & Difficulty to perform the movement (29.1) \\
\hline \multicolumn{3}{|l|}{ Hard palate $(n=66)$} \\
\hline Aspect & Ogival (71.2) & Normal (28.8) \\
\hline \multicolumn{3}{|l|}{ Dental arch $(n=66)$} \\
\hline Anterior open bite & Present (84.8) & Absent (15.2) \\
\hline Lateral cross bite & Absent (62.1) & Present (37.9) \\
\hline Occlusion & Distocclusion (54.1) & Neutrocclusion (32.8) \\
\hline
\end{tabular}

MPS = mucopolysaccharidosis.

* No variable could be evaluated on physical exam in one patient (see Results). In another patient only the stomatognathic system could be evaluated. Therefore, of the 78 patients included in the study, 77 had their stomatognathic structures evaluated and 76 had their stomatognathic functions evaluated.

+ Habitual position represents the position at rest in which lips, tongue and dental arch are found.

₹ Only variables that could be evaluated for more than $50 \%$ of the sample are described. 
Table 3 - Evaluation of stomatognathic functions in patients with MPS*+

\begin{tabular}{|c|c|c|}
\hline Stomatognathic functions & Most frequent finding (\%) & Second most frequent finding $(\%)$ \\
\hline \multicolumn{3}{|l|}{ Suction $(n=50)$} \\
\hline Efficiency & Normal (92) & Inefficient (8) \\
\hline Tongue posture & Normal (88.9) & Protrusion (11.1) \\
\hline Lip posture & Pressed (71.1) & Protrusion (28.9) \\
\hline \multicolumn{3}{|l|}{ Mastication $(n=64)$} \\
\hline Symmetry & Symmetrical (73.7) & Asymmetrical to the left (15.8) \\
\hline Lip position & Separated (65.6) & United (34.4) \\
\hline Speed & Slow (89.8) & Fast (10.2) \\
\hline Mandible mobility & Vertical (92.6) & Normal (7.4) \\
\hline Bite & Anterior (55) & Lateral (45) \\
\hline \multicolumn{3}{|l|}{ Swallowing $(n=67)$} \\
\hline Mentalis muscle tonus & Hyperfunction (96.4) & Normal (3.6) \\
\hline Perioral muscles & Normal (53.7) & Altered (46.3) \\
\hline Lingual projection & Absent (78.5) & Present (21.5) \\
\hline Compensatory movement & Absent (90.9) & Present (9.1) \\
\hline \multicolumn{3}{|l|}{ Breathing $(n=74)$} \\
\hline Mode & Oral (71.6) & Nasal (28.4) \\
\hline Type & Costodiaphragmatic (47.7) & Upper (32.3) \\
\hline Nasal cavities & Normal (70.1) & Obstructed (28.4) \\
\hline \multicolumn{3}{|l|}{ Speech $(n=62)$} \\
\hline Tongue protrusion & Presence (74.2) & Absence (25.8) \\
\hline Phoneme changes & Absence (69.4) & Presence (30.6) \\
\hline Phoneme omission & Absence (85.5) & Presence (14.5) \\
\hline
\end{tabular}

MPS = mucopolysaccharidosis.

* No variable could be evaluated on physical examination in one patient (see Results). In another patient only the stomatognathic system could be evaluated Therefore, of the 78 patients included in the study, 77 had their stomatognathic structures evaluated and 76 had their stomatognathic functions evaluated.

$\ddagger$ Only variables that could be evaluated for more than $50 \%$ of the sample are described.

Table 4 - Distribution, according to type of MPS, of the most frequent changes found in evaluation of the stomatognathic system and functions

\begin{tabular}{|c|c|c|c|c|}
\hline Change & $\begin{array}{c}\text { MPS I }(\mathbf{n}=13 / 14) \\
\text { n (\%)* }\end{array}$ & $\begin{array}{c}\text { MPS II }(\mathbf{n}=35) \\
n(\%)\end{array}$ & $\begin{array}{c}\text { MPS VI (n = 23) } \\
\text { n (\%) }\end{array}$ & $\mathbf{p}$ \\
\hline Hyperfunction of mentalis muscle at rest & $12 / 13(92.3)$ & $29 / 32(90.6)$ & $22 / 22(100)$ & $0.398^{+}$ \\
\hline Habitual tongue position between teeth & $3 / 12(25)$ & $13 / 33(39.4)$ & $18 / 23(78.3)$ & $0.003^{\neq}$ \\
\hline Cheek asymmetry & $6 / 10(60)$ & $23 / 28(82.1)$ & $18 / 22(81.8)$ & $0.309^{+}$ \\
\hline Difficulty in mandible rotation & $6 / 9(66.7)$ & $17 / 21(81)$ & $15 / 18(83.3)$ & $0.652^{+}$ \\
\hline Ogival palate & $9 / 13(69.2)$ & $19 / 28(67.9)$ & $17 / 21(81)$ & $0.569^{\ddagger}$ \\
\hline Anterior open bite & $10 / 11(90.9)$ & $20 / 27(74.1)$ & $23 / 23(100)$ & $0.017^{+\S}$ \\
\hline Suction with pressed lips & $4 / 6(66.7)$ & $21 / 26(80.8)$ & $5 / 11(45.5)$ & $0.083^{+}$ \\
\hline Vertical mastication mode & $6 / 7(85.7)$ & $24 / 24(100)$ & $20 / 21(95.2)$ & $0.127^{+}$ \\
\hline Hyperfunction of mentalis muscle in swallowing & $7 / 8(87.5)$ & $27 / 28(96.4)$ & $17 / 17(100)$ & $0.380^{+}$ \\
\hline Oral breathing mode & $9 / 12(75)$ & $19 / 33(57.6)$ & $21 / 23(91.3)$ & $0.021^{\ddagger \S}$ \\
\hline Tongue protrusion in speech & $7 / 10(70)$ & $21 / 28(75)$ & $17 / 21(81)$ & $0.780^{+}$ \\
\hline
\end{tabular}

MPS = mucopolysaccharidosis

* No physical examination item could be evaluated in one patient with MPS I.

$\dagger$ Fisher's exact test.

$\ddagger$ Chi-square test.

$\S p<0.05$. When Bonferroni's correction was applied, only habitual tongue position between teeth had significant statistical difference between types of MPS. 
such information systematically, using a relatively adequate sample size (considering that MPS are rare diseases) and including determination of frequency of findings between MPS types and evaluation of ERT.

Although many of the alterations found can be explained by the accumulation of GAG in every tissue and by the fact that patients with MPS present generalized skeletal dysplasia often associated with neurological involvement, we put forward the hypothesis, as explained below, that the development of such alterations is also dependent on environmental components (such as maternal breastfeeding time). This would reinforce the potential benefits of pediatric, otorhinolaryngologic, speech therapy, and dental care interventions.

Anamnesis data showed maternal breastfeeding time in Brazilian patients shorter than that recommended by the World Health Organization (24 months), but relatively similar to that of the Brazilian population (10 months). ${ }^{22}$ This shorter breastfeeding time may be considered as a negative point, since breastfeeding, by exercising orofacial musculature and stimulating respiratory, swallowing, mastication and phonation functions, fosters a proper craniofacial development.

Breastfeeding movements also favor lip seal at rest, the correction of physiological mandibular retrognatism and tongue position in the palatine region of central incisive teeth. This muscular balance enables nasal breathing, which puts pressure onto the palate forcing it to lower and expand and generating space for adequate tooth eruption. Therefore, the high prevalence of habitual position of separate lips and tongue between teeth, hyperfunctional mentalis muscle, distocclusion, ogival palate and anterior open bite found in the sample could be partially explained by the relatively short time of breastfeeding. The relatively long use of the baby bottle could also contribute to these findings. A study states that the use of the baby bottle has a negative impact on orofacial development. ${ }^{23}$ The sample used pacifiers for a long time, and it is known that there is an association between the use of pacifier and a shorter maternal breastfeeding time. ${ }^{24}$ As previously mentioned, patients with MPS are diagnosed in Brazil with median age of 76 months, ${ }^{21}$ that is, after the breastfeeding period. However, clinical manifestations usually start on average at the age of 18 months, ${ }^{21}$ in other words, also after the breastfeeding period. Thus, one would not expect the breastfeeding period of patients with MPS to be different from that of the Brazilian population in general. And this is accordance with the findings of the present study.

Another interesting finding concerns ingestion of pasty food only until the age of 2 years, which was relatively frequent. We know that this contributes to the occurrence of malocclusion (open and crossed bite), low-quality mastication (separate lips, very slow mastication) as well as alterations in the development of the stomatognathic system, ${ }^{25}$ these alterations were frequent among the patients assessed in the present study .

The association between MPS and occurrence of adenotonsillar hypertrophy, enlarged tongue and limitation of mouth opening/mandible anomalies is well known. 5,26-30 Although it has not been possible to evaluate prevalence of adenotonsillar hypertrophy, the other findings were frequent in the sample. They bring patients an increased risk of oral breathing and obstructive apnea and other sleep disorders, in addition to a greater need of adenoidectomy and tonsillectomy, ${ }^{26-30}$ also present in this sample. However, it is important to stress that most patients had normal mandible opening. In the authors' opinion, prevalence of alterations in this item, as well as in that relative to suction efficiency, in which most patients were also classified as normal, is underestimated - evaluations of mandible mobility and suction presented some difficulties on physical examination, which can be inferred from the lower sample size of these variables in comparison with the others. Therefore, the majority of patients were those who collaborated with the examination, that is, those who potentially had a milder somatic involvement and absence of cognitive deficit.

The analysis performed to identify the differences between clinical manifestations and the type of MPS showed the presence a higher number of patients with MPS VI with a habitual position of the tongue between the teeth when compared to MPS I and MPS II patients. This finding may probably be explained by the fact that in the present sample MPS VI patients were the most severely compromised from the somatic perspective, being even the only patients with tracheostomy and severe visual deficit. If Bonferroni's correction had not been applied, open bite and oral breathing would also be considered more frequent in this type of MPS. This suggests that these three manifestations (habitual tongue position between the teeth, open bite and oral breathing) are related.

Considering patients with MPS I, II and VI submitted or not to ERT, there was statistically significant difference in relation to oral breathing, which was more frequent in the group not exposed to ERT. One limitation of such finding is that data collection and analysis were not blinded. However, it is in accordance with data from the literature, which suggest a positive clinical effect of ERT on upper airways. ${ }^{10-12}$

A small number of patients were undergoing speech therapy during the study period. Among the possible reasons for that are difficulty to access this form of treatment; lack of knowledge of the high prevalence of speech abnormalities in patients with MPS by assistant physicians; and absence of evidence on the benefits of such intervention. ${ }^{15}$ The rational of speech therapy treatment for orofacial motricity in patients with MPS would be that, if applied correctly, it would increase muscle tonus, change some functional patterns and prevent deviations in craniofacial development. also, the sooner 
the diagnosis of these patients is established more the phonoaudiologist will be able to help prevent certain clinical manifestations of this disease. In this manner, guidance to parents, especially in issues such as breastfeeding and mastication of adequate food consistency could perhaps reduce the frequency of some of the findings of the present study. These hypotheses should be confirmed by future studies.

In general, the data obtained in this study reinforce the circular relationship "cause-effect-cause-effect" present in MPS: the high frequency of alterations in structures of the stomatognathic system is associated with a high frequency of alterations in stomatognathic functions, which in turn can worsen structural alterations. In the authors' opinion, only a combined and coordinated action by all health professionals involved in providing care to patients with MPS can break this circular relationship and provide better quality of life to patients.

\section{Acknowledgments}

The authors would like to thank CAPES, MPS-Brazil Network, statistical support at GPPG-HCPA, patients included in the study and professionals at the Medical Genetics Service of HCPA, especially Dr. Roberto Giugliani and members of the MPS team.

\section{References}

1. Beck M. Mucopolysaccharidoses and oligosaccharidoses. In: Fernandes J, Saudubray M, Van der Berghe G, editors. Inborn metabolic diseases, diagnosis and treatment. 3rd ed. New York: Springer; 2000. p. 415-21.

2. Nelson J. Incidence of the mucopolysaccharidoses in Northern Ireland. Hum Genet. 1997;101:355-8.

3. Pastores GM, Arn P, Beck M, Clarke JT, Guffon N, Kaplan P, et al. The MPS I registry: design, methodology, and early findings of a global disease registry for monitoring patients with Mucopolysaccharidosis Type I. Mol Genet Metab. 2007;91:37-47.

4. Ashworth JL, Biswas S, Wraith E, Lloyd IC. Mucopolysaccharidoses and the eye. Surv Ophthalmol. 2006;51:1-17.

5. Onçağ G, Ertan Erdinç AM, Cal E Multidisciplinary treatment approach of Morquio syndrome (Mucopolysaccharidosis Type IVA). Angle Orthod. 2006;76:335-40.

6. Cardoso-Santos A, Azevedo AC, Fagondes S, Burin MG, Giugliani R, Schwartz IV. Mucopolysaccharidosis type VI (Maroteaux-Lamy syndrome): assessment of joint mobility and grip and pinch strength. J Pediatr (Rio J). 2008;84:130-5.

7. Herskhovitz E, Young E, Rainer J, Hall CM, Lidchi V, Chong K, et al. Bone marrow transplantation for Maroteaux-Lamy syndrome (MPS VI): long-term follow-up. J Inherit Metab Dis. 1999;22:50-62.

8. Vellodi A, Young EP, Cooper A, Wraith JE, Winchester B, Meaney $C$, et al. Bone marrow transplantation for mucopolysaccharidosis type I: experience of two British centres. Arch Dis Child. 1997;76:92-9.

9. Peters C, Shapiro EG, Anderson J, Henslee-Downey PJ, Klemperer MR, Cowan MJ, et al. Hurler syndrome: II. Outcome of HLAgenotypically identical sibling and HLA-haploidentical related donor bone marrow transplantation in fifty-four children. The Storage Disease Collaborative Study Group. Blood. 1998; 91:2601-8.

10. Wraith JE, Clarke LA, Beck M, Kolodny EH, Pastores GM, Muenzer J, et al. Enzyme replacement therapy for mucopolysaccharidosis I: a randomized, double-blinded, placebo-controlled, multinational study of recombinant human alpha-L-iduronidase (laronidase). J Pediatr. 2004;144:581-8.
11. Muenzer J, Wraith JE, Beck M, Giugliani R, Harmatz P, Eng CM, et al. A phase II/III clinical study of enzyme replacement therapy with idursulfase in mucopolysaccharidosis II (Hunter syndrome). Genet Med. 2006;8:465-73.

12. Harmatz P, Giugliani R, Schwartz I, Guffon N, Teles EL, Miranda MC, et al. Enzyme replacement therapy for mucopolysaccharidosis VI: a phase 3, randomized, double-blind, placebo-controlled, multinational study of recombinant human $\mathrm{N}$ acetylgalactosamine 4-sulfatase (recombinant human arylsulfatase B or rhASB) and follow-on, open-label extension study. J Pediatr. 2006;148:533-9.

13. Cho YS, Kim JH, Kim TW, Chung SC, Chang SA, Jin DK. Otologic manifestations of Hunter syndrome and their relationship with speech development. Audiol Neurootol. 2008;13:206-12.

14. Wallace SP, Prutting CA, Gerber SE. Degeneration of speech, language, and hearing in a patient with mucopolysaccharidosis VII. Int J Pediatr Otorhinolaryngol. 1990;19:97-107.

15. Zimmer D, Kraychete B, Acosta A. Phonoaudiological Findings in patients with mucopolysaccharidoses at the professor Edgard Santos Hospital: establishing a follow up protocol. II Congresso Latino Americano de Enfermidades Lisossômicas (COLATEL); 2008 Dez 14-16; Salvador, Brasil. p. 18-9.

16. Bianchini EM. Avaliação fonoaudiológica da motricidade oral: distúrbios miofuncionais orofaciais ou situaç̃ões adaptativas. Rev Dental Press Ortodon Ortop Facial. 2001;6:73-82.

17. Junqueira P. Avaliação miofuncional. In: Marchesan IQ Fundamentos em fonoaudiologia: aspectos clínicos da motricidade oral. Rio de Janeiro: Guanabara Koogan; 1998. p.12-21.

18. Morales RC. Terapia de regulação orofacial. São Paulo: Memnon; 1999.

19. Marchesan IQ. Motricidade Oral: visão clinica do trabalho fonoaudiológico integrado com outras especialidades. São Paulo: Pancast; 1993.

20. Neufeld EF, Muenzer J. The mucopolisaccharidosis. In: Scriver $\mathrm{CR}$, Beandet AL, Sly S, Valle D, Childs B, Kinzler KW, et al, eds. The metabolic and molecular basis of inherited disease. 8th ed. New York: McGraw-Hill; 2001. p.3421-52.

21. Vieira T, Schwartz I, Muñoz V, Pinto L, Steiner C, Ribeiro M, et al. Mucopolysaccharidoses in Brazil: what happens from birth to biochemical diagnosis? Am J Med Genet A. 2008;146A:1741-7.

22. Venancio SI. Dificuldades para o estabelecimento da amamentação: o papel das práticas assistenciais das maternidades. J Pediatr (Rio J). $2003 ; 79: 1-2$

23. Carrascoza KC, Possobon RdeF, Tomita LM, Moraes AB. Consequences of bottle-feeding to the oral facial development of initially breastfed children. J Pediatr (Rio J). 2006;82:395-7.

24. Soares ME, Giugliani ER, Braun ML, Salgado AC, Oliveira AP, de Aguiar PR. Uso de chupeta e sua relação com o desmame precoce em população de crianças nascidas em Hospital Amigo da Criança. J Pediatr (Rio J). 2003;79:309-16.

25. Pena CR, Pereira MM, Bianchini EM. Características do tipo de alimentação e da fala de crianças com e sem apinhamento dentário. Rev CEFAC. 2008;10:58-67.

26. Simmons MA, Bruce IA, Penney S, Wraith E, Rothera MP. Otorhinolaryngological manifestations of the mucopolysaccharidoses. Int J Pediatr Otorhinolaryngol. 2005;69:589-95.

27. Yeung AH, Cowan MJ, Horn B, Rosbe KW. Airway management in children with mucopolysaccharidoses. Arch Otolaryngol Head Neck Surg. 2009;135:73-9.

28. Salles C, Fernandes L, Acosta A. Prevalência da Hipertrofia Adenotonsilar em Portadores de Mucopolissacaridose. II Congresso Latino Americano de Enfermidades Lisossômicas (COLATEL); 2008 Dez 14-16; Salvador, Brasil. p.16-7.

29. Ribeiro EM, de Bruin V, Silva ACB. Characteristics of sleep disorders in patients with mucopolysaccharidoses. II Congresso Latino Americano de Enfermidades Lisossômicas (COLATEL); 2008 Dez 14-16; Salvador, Brasil. p. 50-1.

30. Greck APBS, Torres MFM, da Costa SV, Sá NBC, Acosta AX. Implantação da Assistência Odontológica aos Pacientes com Mucopolissacaridose na Unidade de Referência do Estado da Bahia. II Congresso Latino Americano de Enfermidades Lisossômicas (COLATEL); 2008 Dez 14-16; Salvador, Brasil. p. 14-5.

Correspondence:

Ida Vanessa Doederlein Schwartz

Serviço de Genética Médica

Hospital de Clínicas de Porto Alegre

Rua Ramiro Barcelos, 2350

CEP 90035-003 - Porto Alegre, RS - Brazil

Tel.: +55 (51) 2101.8309

E-mail: ischwartz@hcpa.ufrgs.br 